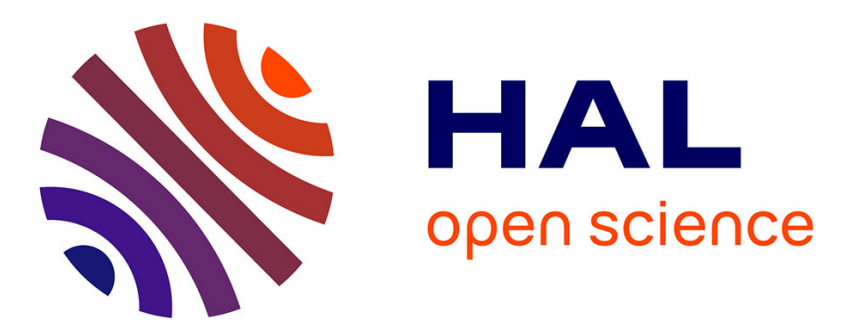

\title{
Spatio-temporal interpolation of Sea Surface Temperature using high resolution remote sensing data
}

\author{
Redouane Lguensat, Pierre Tandeo, Ronan Fablet, René Garello
}

\section{To cite this version:}

Redouane Lguensat, Pierre Tandeo, Ronan Fablet, René Garello. Spatio-temporal interpolation of Sea Surface Temperature using high resolution remote sensing data. OCEANS 2014 St John's: MTS/IEEE international conference, Sep 2014, St. John'S, Canada. pp.1 - 4, 10.1109/OCEANS.2014.7002988 . hal-01188863

\section{HAL Id: hal-01188863 https://hal.science/hal-01188863}

Submitted on 31 Aug 2015

HAL is a multi-disciplinary open access archive for the deposit and dissemination of scientific research documents, whether they are published or not. The documents may come from teaching and research institutions in France or abroad, or from public or private research centers.
L'archive ouverte pluridisciplinaire HAL, est destinée au dépôt et à la diffusion de documents scientifiques de niveau recherche, publiés ou non, émanant des établissements d'enseignement et de recherche français ou étrangers, des laboratoires publics ou privés. 


\title{
Spatio-temporal interpolation of Sea Surface Temperature using high resolution remote sensing data
}

\author{
Redouane Lguensat, Pierre Tandeo, Ronan Fablet and René Garello \\ Institut Mines-Telecom - Telecom Bretagne \\ CNRS UMR 6285 LabSTICC - Pôle CID \\ Technopôle Brest Iroise - CS 83818 \\ 29238 BREST Cedex - FRANCE \\ Email: redouane.lguensat@telecom-bretagne.eu
}

\begin{abstract}
In this work, we present a statistical model to generate relevant reanalysis of geophysical parameters. In particular, we use a stochastic equation to control the temporal and spatial variability of the signal and we take into account the possible error of the observations. We resolve the system iteratively using an ensemble Kalman filter and smoother. We apply the methodology to remote sensing data of Sea Surface Temperature (SST). We use high resolution SST maps provided by an infrared sensor, sensible to the presence of cloud. Comparing the results with the reference SST reanalysis, we demonstrate the capability of our approach to interpolate missing data and keep into account the spatial and temporal consistency of the SST signal.
\end{abstract}

\section{INTRODUCTION}

Sea Surface Temperature (SST) is a key geophysical parameter for constraining the exchange of energy and moisture between the ocean and the atmosphere (see e.g. [1] and references therein). SST is also a good tracer of the ocean surface dynamics and can be very useful for the surface current retrievals (cf. [2]). Satellite infrared sensors provide high resolution images of SST in the global ocean. However, infrared measurements are contaminated by the presence of clouds and the results are large gaps in the SST maps. The main goal of this paper is to interpolate these data.

The classical approach to interpolate SST data is to use the optimal interpolation algorithm with large spatial correlation lengths and without specifying clearly the temporal dependency of the SST signal (see e.g. [3]). In this paper, we use previous results for the characterization of the SST variability from remote sensing data, taking into account (i) the irregular temporal sampling due to clouds and the temporal correlation lengths (cf. [4]) and (ii) the anisotropic spatial variability due to surface currents (cf. [5]). Then, we assimilate high resolution infrared SST data with these statistically-learned spatial and temporal dynamics using an ensemble Kalman filter and smoother.

The paper is organized as follows. Section II presents the remote sensing data. Section III describes our spatio-temporal interpolation method. In Section IV, the application to satellite observations is evaluated. We further discuss and summarize the key results of our investigations in Section V.

\section{DATA}

As high spatial resolution infrared observations $\left(0.05^{\circ}\right)$, we use SST data provided by the Advanced Very High Resolution Radiometer (AVHRR) onboard the METOP satellite (cf. [6]). We use night-time measurements to avoid the diurnal cycle and good-quality pixel data corresponding to best proximity confidence levels (flags 4 and 5). The resulting METOP-AVHRR SST fields are clearly non-stationary with important seasonal components. The non-stationary components have complex features and we could not find any appropriate parametric model to describe them.

To remove these components, we used the daily $0.25^{\circ}$ resolution Optimal Interpolation Version 2 (OIV2) analysis provided by the National Climatic Data Center (NCDC). This analysis is derived from different satellite sources independent of METOP-AVHRR data (cf. [7]). We assume that they provide a good estimate of the low-variations of the SST conditions. In this paper, we interpolate the SST anomaly given by the difference between the METOP-AVHRR and the corresponding OIV2 fields.

To compare and validate our spatio-temporal interpolation, we use a $0.05^{\circ} \mathrm{SST}$ product provided by Met Office and the Operational Sea Surface Temperature and Sea Ice Analysis system (OSTIA, cf. [3]). This OSTIA product corresponds to the long term reanalysis created for the European Space Agency (ESA) SST Climate Change Initiative (CCI) project. It is considered as the high resolution complete fields SST reference.

Hereafter, we consider the Malvinas and Brazilian currents, off the Argentinian coasts, during the year 2008. This place is interesting to test our methodology due to strong surface currents and resulting strong SST variability.

\section{MODEL}

As described in [4], we use a discrete time version of an Ornstein-Uhlenbeck process to model the temporal evolution of the state noted as $x$ and corresponding to the true SST anomaly. Here, we additionally take into account the neighborhood introducing an anisotropic and exponential spatial covariance $\Sigma$ in the formulation. The state equation is finally 
given by

$$
x\left(t_{k}\right)=M x\left(t_{k-1}\right)+\eta\left(t_{k}\right)
$$

with $M=\exp \left(-\lambda\left(t_{k}-t_{k-1}\right)\right)$ and $\eta\left(t_{k}\right)$ a Gaussian white noise with covariance $Q=\Sigma-M \Sigma M^{\prime}$. Using this formulation, supposing that the temporal lag is negligible, the autocorrelation matrix $M$ will be close to identity and error covariance $Q$ will be the null matrix. At the contrary, when temporal lag is significant (e.g. several days without data), all the variability is spatial and contained in $\Sigma$. Therefore, the proposed model mainly uses the temporal variability and secondarily uses the neighborhood. In Eq. (1), the statistical parameters $\lambda$ (related to the autoregressive process) and $\Sigma$ (characterizing the spatial anisotropy) are different for each location and were estimated on the same remote sensing data respectively in [4] and [5].

Then, we relate the state to the observations $y$, corresponding to SST anomalies between METOP-AVHRR and OIV2 as presented in Section II, by

$$
y\left(t_{k}\right)=H x\left(t_{k}\right)+\epsilon\left(t_{k}\right)
$$

where $H$ is a matrix operator ( 0 for unavailable data, 1 for presence), $\epsilon\left(t_{k}\right)$ is a Gaussian white noise and $R$ is the SST variance provided by the satellite sensor.

To assimilate the METOP-AVHRR observations in Eq. (2) with the statistically learned spatio-temporal model given in Eq. (1), we use a Monte Carlo version of the classical Kalman filter (cf. [8]) and smoother (cf. [9]). It is widely used in geophysical studies and especially to high dimensional problems (as here, due to the high number of pixels, $400 \times 400$ ) or nonlinear state/observation equations (see [10] for more details). The results is a complete sequence of reanalyzed $0.05^{\circ}$ SST fields in the Malvinas region over the year 2008.

\section{RESUlTS}

In this Section, we compare our spatio-temporal interpolation results to the reference SST reanalysis provided by the OSTIA system and presented in Section II. In Fig. 1, we plot a snapshot of the SST image sequence with their corresponding gradients. The results indicate that we are able to track the fine oceanic structures like fronts or eddies such as the one identified in our interpolation at the bottom right of the image. At this date, even if it is not visible by the METOP-AVHRR sensor due to the presence of clouds, our reanalysis is able to reveal the eddy due to its presence in past and future satellite images. This is due to the large temporal autocorrelation of the SST signal in this region. It is well taken into account in the spatio-temporal dynamical equation in Eq. (1) whereas the OSTIA system is mainly using the spatial information in its multi-scale optimal interpolation (see [3] for more details).

Then, in Fig. 2(a), we show that our spatio-temporal interpolation is more consistent with the METOP-AVHRR observations than the OSTIA product in terms of gradient distribution. Indeed, the raw METOP-AVHRR observations and our spatio-temporal interpolation have a mode of the gradient norm close to $0.02 \mathrm{~K} / \mathrm{km}$ whereas the one for OSTIA is reduced by half. We also compare in Fig. 2(b) the spectral slopes of the two reanalysis. For each of them, there is no energy between 5 and $25 \mathrm{~km}$. This is due to the spatial correlation length defined in the OSTIA system and the $\Sigma$

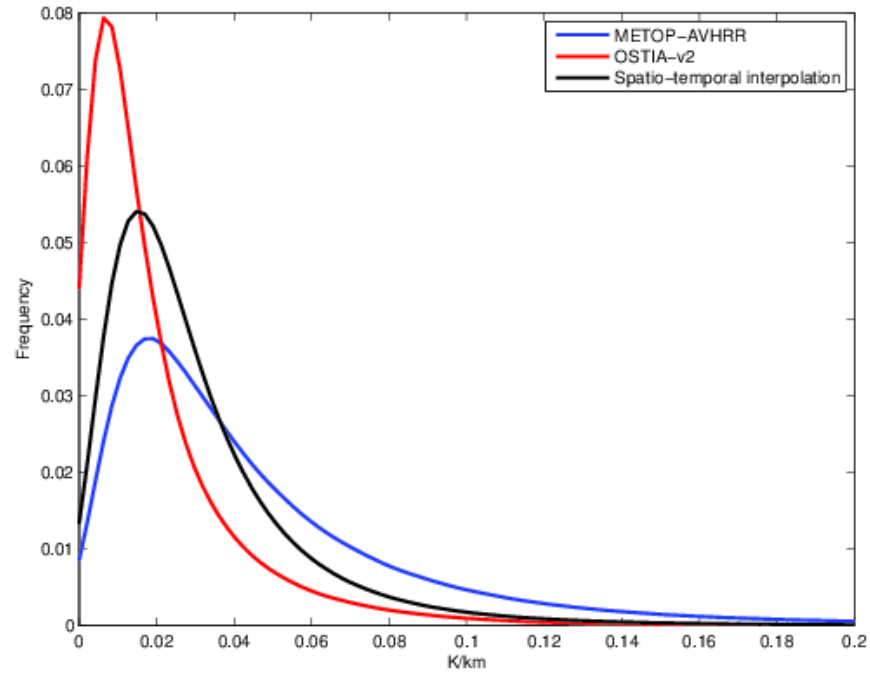

(a) Norm of the SST gradients

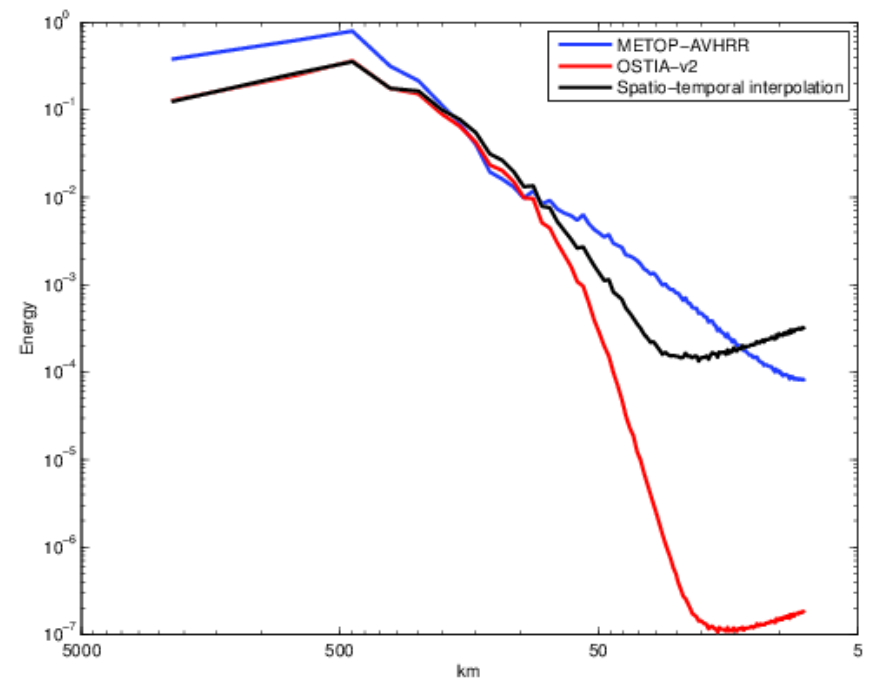

(b) Spectral slopes

Fig. 2. Diagnostic results for the characterization of the OSTIA-v2 reanalysis (red), the METOP-AVHRR observations (blue) and our spatio-temporal reanalysis (black). The different curves are averaged over the year 2008 in the Malvinas current.

covariance matrix in Eq. (1). Then, for spatial scales between 25 and $100 \mathrm{~km}$, the spectral slope and the energy of our spatiotemporal analysis are consistent with those of the METOPAVHRR observations.

\section{CONCLUSION AND PERSPECTIVES}

In this paper, we use high resolution data $\left(0.05^{\circ}\right)$ provided by the infrared METOP-AVHRR sensor to generate realistic time series of SST maps in the Malvinas in a complete year. We use a sequential filtering and smoothing method mixing two main information: (i) a spatio-temporal dynamical equation preliminarily fitted in previous works and (ii) a classical observation equation to take into account the quality of the remote sensing data. The results of the interpolation indicate a general continuity in space and time, allowing the tracking of submesoscale structures in the ocean. This is mainly due to the temporal consistency of the SST signal (certainly more 

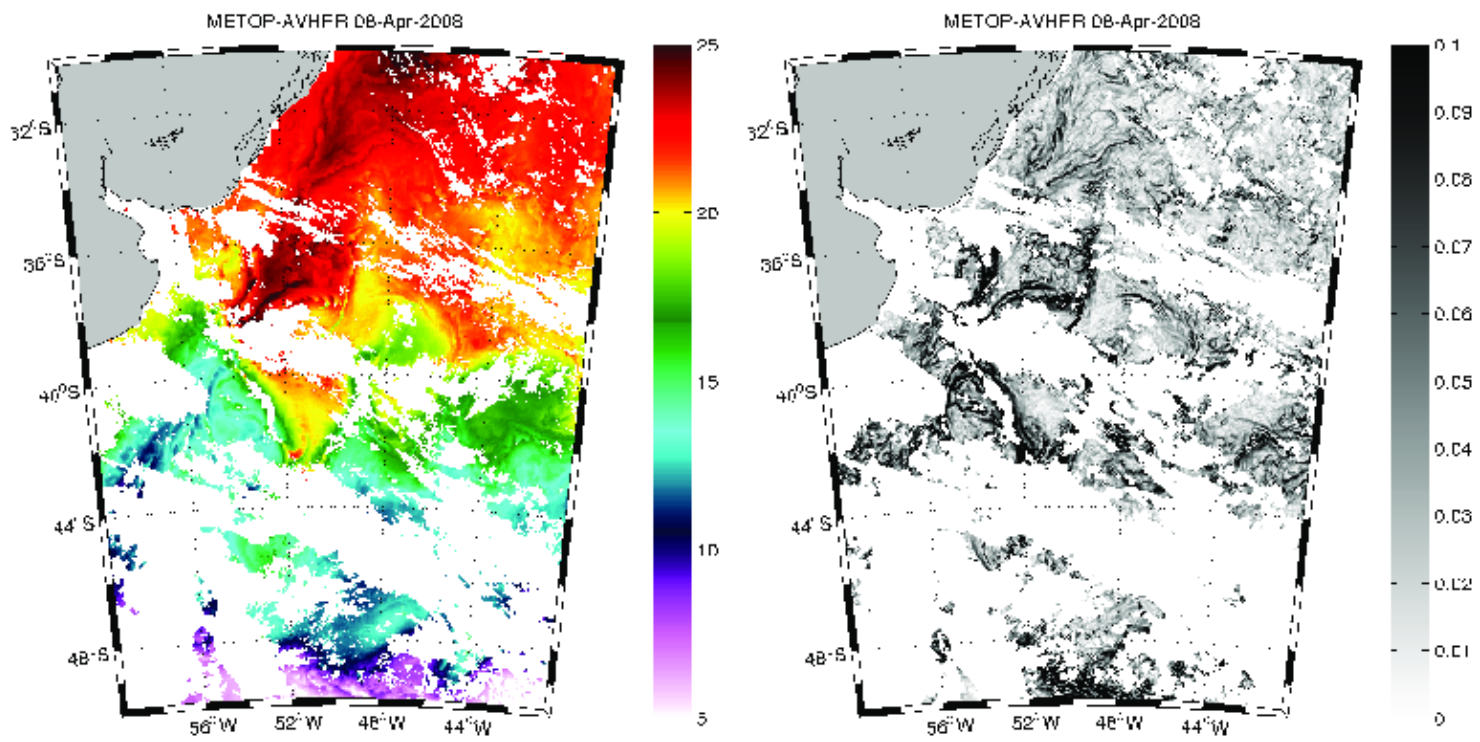

(a) METOP-AVHRR
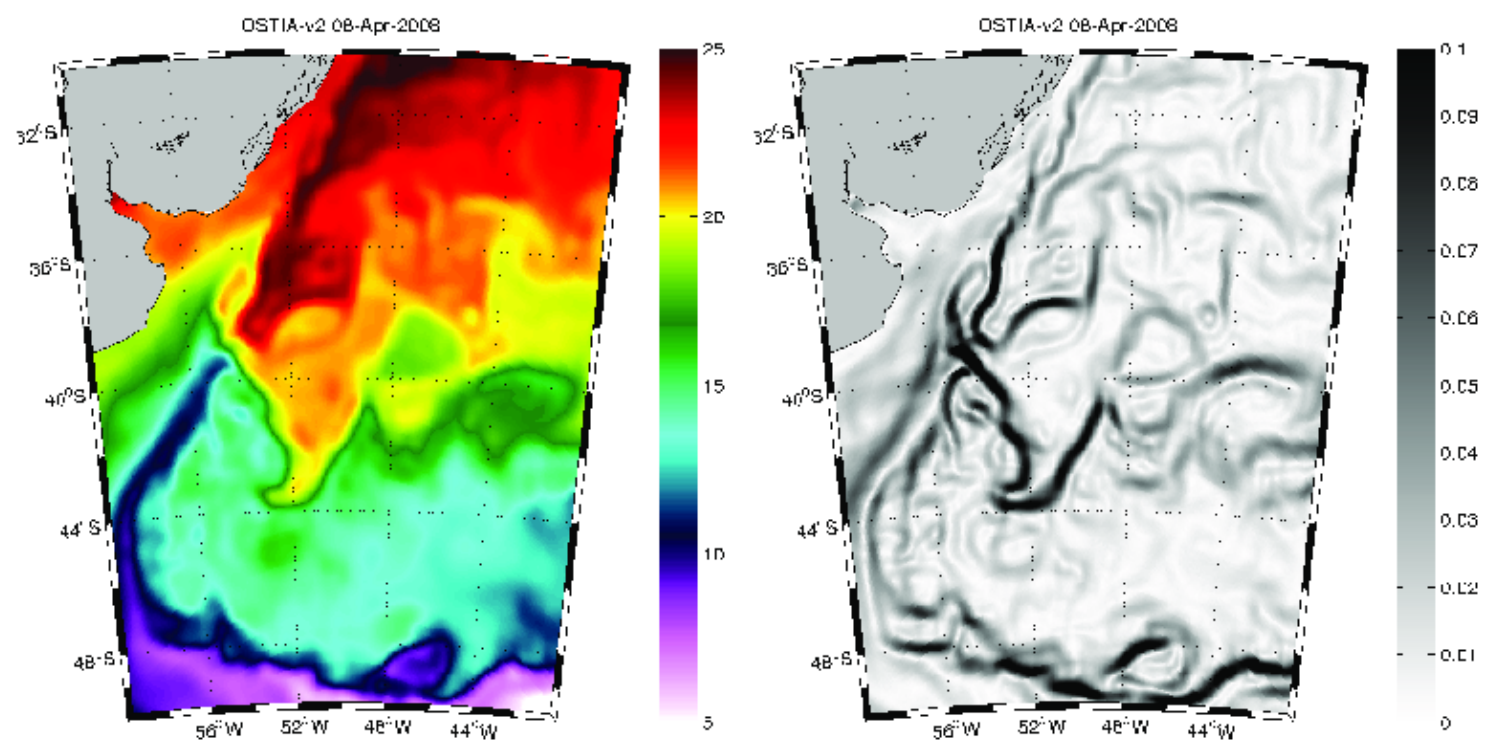

(b) OSTIA analysis
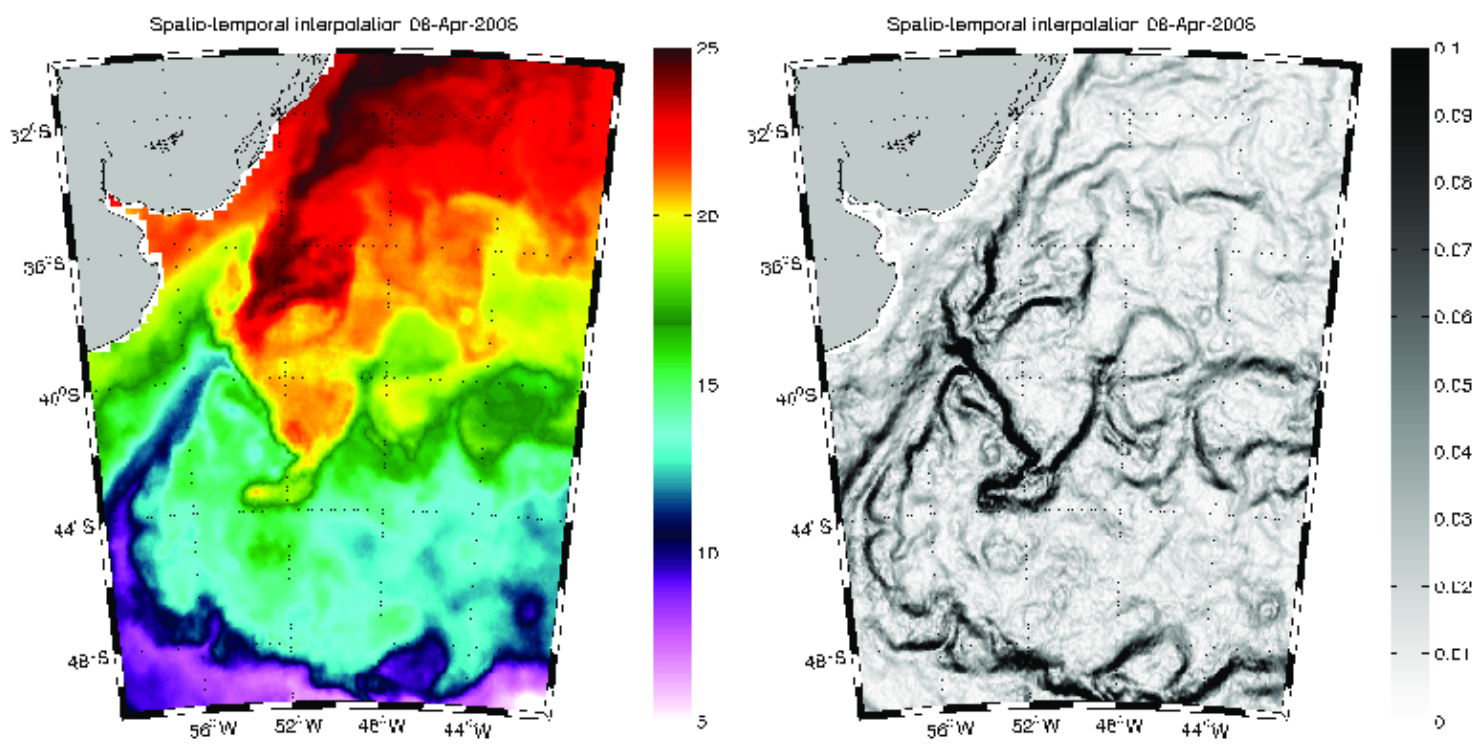

(c) Spatio-temporal interpolation

Fig. 1. Raw SST and results of SST interpolations (left) and their corresponding norm of gradients (right) in the Malvinas current the $8^{t h}$ of April 2008. 
important than the spatial one). We also compare our spatiotemporal results to the reference given by the OSTIA system. We show that our analysis is more consistent to the METOPAVHRR data in terms of spectral slopes and norm of the SST gradients. All indicates that our algorithm can be used as an alternative to the classical optimal interpolation such as the one used in the OSTIA system. Additionally, on the basis of the results, something is questionable: is it necessary to mix the information of several data sources (in situ, microwave and infrared sensors) with possible biases whereas using only one satellite sensor seems sufficient?

\section{ACKNOWLEDGMENTS}

The OIV2 data are provided by the NOAA/OAR/ESRL PSD, Boulder, Colorado, USA, from their web site at http:// www.esrl.noaa.gov/psd/. Then, the METOP-AVHRR data from the EUMETSAT Satellite Application Facility on Ocean and Sea Ice are accessible through the SAF's homepage: http:// www.osi-saf.org. Finally, the OSTIA data are corresponding to the long term reanalysis created for the ESA SST CCI project with the OSTIA system. We are grateful to Jonah RobertsJones from the Met Office service to providing these data.

\section{REFERENCES}

[1] C.J. Donlon, P.J. Minnett, C. Gentemann, T.J. Nightingale, I.J. Barton, B. Ward, and M.J. Murray, "Toward improved validation of satellite sea surface skin temperature measurements for climate research.," Journal of Climate, vol. 15, no. 4, 2002.
[2] P. Tandeo, B. Chapron, S. Ba, E. Autret, and R. Fablet, "Segmentation of mesoscale ocean surface dynamics using satellite sst and ssh observations," Geoscience and Remote Sensing, IEEE Transactions on, vol. 52, no. 7, pp. 4227-4235, July 2014.

[3] C.J. Donlon, M. Martin, J. Stark, J. Roberts-Jones, E. Fiedler, and W. Wimmer, "The operational sea surface temperature and sea ice analysis (ostia) system," Remote Sensing of Environment, vol. 116, pp. 140-158, 2012.

[4] P. Tandeo, P. Ailliot, and E. Autret, "Linear gaussian state-space model with irregular sampling: application to sea surface temperature," Stochastic Environmental Research and Risk Assessment, vol. 25, no. 6, pp. 793-804, 2011.

[5] P. Tandeo, E. Autret, B. Chapron, R. Fablet, and R. Garello, "Sst spatial anisotropic covariances from metop-avhrr data," Remote Sensing of Environment, vol. 141, pp. 144-148, 2014.

[6] P. Le Borgne, G. Legendre, and A. Marsouin, "Operational sst retrieval from metop/avhrr," in Proc. 2007 EUMETSAT Conf., Amsterdam, the Netherlands, 2007.

[7] R. W. Reynolds, T. M. Smith, C. Liu, D. B. Chelton, K. S. Casey, and M. G. Schlax, "Daily high-resolution-blended analyses for sea surface temperature," Journal of Climate, vol. 20, no. 22, pp. 5473-5496, 2007.

[8] G. Evensen, "The ensemble kalman filter: Theoretical formulation and practical implementation," Ocean dynamics, vol. 53, no. 4, pp. 343-367, 2003.

[9] Geir Evensen and Peter Jan Van Leeuwen, "An ensemble kalman smoother for nonlinear dynamics," Monthly Weather Review, vol. 128, no. 6, pp. 1852-1867, 2000

[10] L. Bertino, G. Evensen, and H. Wackernagel, "Sequential data assimilation techniques in oceanography," International Statistical Review, vol. 71, no. 2, pp. 223-241, 2003. 